\title{
Possible Dependence of Climate on Atmospheric Mass: A Convection-Circulation-Cloud Coupled Feedback $\mathscr{O}$
}

\author{
JUNYAN XIONG, ${ }^{\mathrm{a}}$ JUN YANG, ${ }^{\mathrm{a}}$ AND Ji NIE ${ }^{\mathrm{a}}$

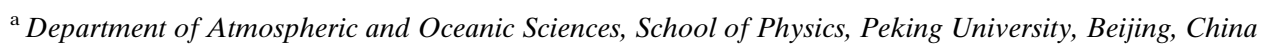

(Manuscript received 23 January 2020, in final form 24 August 2020)

\begin{abstract}
The total mass of the atmosphere [or equivalently, the background surface pressure (SP)] may have varied significantly over the evolutionary histories of Earth and other planets. Atmospheric mass can affect climate by modifying physical processes, including shortwave scattering, the emissivity of greenhouse gases, the atmospheric heat capacity, and surface fluxes. We apply a three-dimensional global climate model to explore the dependence of climate on SP over the range of 0.5-2.5 bar. Our simulations show an intriguing, nonmonotonic dependence of climate on SP. Over the SP range of 0.5-0.9 and 1.5-2.5 bar, the surface temperature increases with SP; however, over the SP range of 0.9-1.5 bar, the surface temperature decreases with SP. The negative correlation is due to a convection-circulation-cloud coupled feedback. As SP increases, the moist adiabatic lapse rate increases, leading to upper-troposphere cold anomalies in the tropics and middle latitudes that increase the midlatitude baroclinicity and eddy activity. In association with these changes, the eddy-driven jet is strengthened and shifts equatorward, and two separate westerly jets merge into a single jet. These abrupt circulation changes result in an equatorward shift of the midlatitude cloud belt and reduction of polar clouds, which induce strong negative cloud radiative forcing that cools the climate. Our results demonstrate that the regime transition of flow state (e.g., the merge of jets here) may induce large anomalies in clouds and radiative forcing, resulting in nonlinear climate responses.
\end{abstract}

KEYWORDS: Atmospheric circulation; Cloud forcing; Convection; Dynamics; Paleoclimate; Planetary atmospheres

\section{Introduction}

The mass of the atmosphere determines the background surface pressure (SP), and it is safely considered constant for the ongoing climate change. However, records of paleoclimate proxies suggest that the atmospheric mass of Earth may have varied significantly over geological time scales. For example, atmospheric $\mathrm{O}_{2}$, which makes up $21 \%$ of the present-day atmosphere, was negligible before the Great Oxidation Event (Bekker et al. 2004). Estimates of $\mathrm{N}_{2}$ in the early atmosphere range from about 0.5 to 3 bar (Goldblatt et al. 2009; Som et al. 2016). The atmospheric mass has been proposed to be, at least, a partial resolution to some paleoclimate problems. One example is the famous faint young sun paradox (Sagan and Mullen 1972). During the Archean, the solar insolation was only approximately $75 \%$ of its current value, and higher atmospheric mass has been proposed to help prevent Earth from being completely frozen (Goldblatt et al. 2009; Charnay et al. 2013; Chemke et al. 2016). The variation in atmospheric mass is common during the evolution of other planets. For instance, the persistent loss of Mars's atmosphere has reduced its mass from 1 to 2 bar in its early stage to the present-day value of 0.006 bar (Lammer and Bauer 1991). Atmospheric mass may play a key role in planetary habitability (e.g., Seager 2013). All of the above considerations inspire us to investigate the dependence of climate on atmospheric mass.

Supplemental information related to this paper is available at the Journals Online website: https://doi.org/10.1175/JAS-D-200022.s1.

Corresponding author: Ji Nie, jinie@pku.edu.cn
Let us consider the possible pathways of how atmospheric mass may affect Earth's climate. Without being coupled with thermodynamics, large-scale atmospheric motions are independent of atmospheric mass: the governing equations can be rescaled to absorb atmospheric mass changes (Frierson 2005; Thomson and Vallis 2019). However, atmospheric mass can affect several thermodynamical processes, thus cause further changes in dynamics. Changes in the masses of radiatively active gases, such as $\mathrm{CO}_{2}, \mathrm{CH}_{4}$, and $\mathrm{O}_{3}$ (the abundance of water vapor critically depends on temperature and thus is not viewed as an external factor), can effectively modify radiative transfer and change the global climate. Changes in the masses of radiatively inactive gases, such as $\mathrm{N}_{2}$ and $\mathrm{O}_{2}$, which make up $\sim 99 \%$ of Earth's atmospheric mass, can indirectly cause changes in the radiative budget. Adding $\mathrm{N}_{2}$ or $\mathrm{O}_{2}$ to the atmosphere enhances the shortwave Rayleigh scattering, but also broadens the absorption lines of greenhouse gases (i.e., the pressure broadening effect), leading to a positive net radiative effect (Pierrehumbert 2010; Wolf and Toon 2014). Moreover, atmospheric mass affects the temperature stratification. The increase of SP leads to the increase of moist adiabatic lapse rate (Thomson and Vallis 2019; Nie et al. 2019), and the increase in the atmospheric heat capacity that reduces radiative cooling in the low levels (Chemke et al. 2016; Chemke and Kaspi 2017, CK17 hereafter). The former is more relevant in the tropics where convection maintains temperature profiles close to moist adiabatic, while the latter is more relevant for the extratropics. In addition, atmospheric mass may affect subgrid-scale processes, such as surface fluxes (Thomson and Vallis 2019).

Several previous studies have investigated the effects of atmospheric mass on Earth's climate with models of varying complexity. Using a simple radiative-convective column model, 
TABLE 1. The experimental groups.

\begin{tabular}{lccl}
\hline \hline \multicolumn{1}{c}{ Experimental group } & Cloud radiative effect & Sea ice & $\mathrm{CO}_{2}$ concentration \\
\hline Default group (DG) & Yes & No & Fixed partial pressure \\
$\mathrm{SG}_{\text {ice }}$ & Yes & Yes & Fixed partial pressure \\
$\mathrm{SG}_{\mathrm{CO} 2}$ & Yes & Yes & Fixed volume mixing ratio \\
$\mathrm{SG}_{\text {cld }}$ & No & No & Fixed partial pressure \\
\hline
\end{tabular}

Goldblatt et al. (2009) suggested that a higher $\mathrm{N}_{2}$ level enhanced the greenhouse effect by the pressure broadening effect and helped warm the early Earth. Limited-domain convectionresolving simulations also indicated that increasing atmospheric mass led to a warmer surface (Molnar and Emanuel 1999; Hu and Boos 2017; Nie et al. 2019). However, climate feedbacks due to large-scale circulation changes are excluded from these limiteddomain simulations. Using a 3D global climate model (GCM), Chemke et al. (2016) and CK17 suggested that the radiative effect of atmospheric mass caused changes in the tropospheric temperature gradient and atmospheric circulations. Their results provided valuable guidance, although the processes neglected in the idealized model [e.g., more realistic representation of convection and the cloud radiative effect (CRE)] may modify the picture. Several GCM studies with sophisticated radiation and cloud physics under realistic configurations of orography have consistently suggested that a higher atmospheric mass leads to significant warming; for example, a doubling of atmospheric pressure produces a warming of $\sim 7 \mathrm{~K}$ (Charnay et al. 2013), and a pressure of 2.4 bar $\mathrm{N}_{2}$ leads to surface warming of 9.7 K (Wolf and Toon 2013).

In this study, we mainly consider the scenario in which the atmospheric mass change is due to changes in the masses of radiatively inactive species (i.e., $\mathrm{N}_{2}$ and $\mathrm{O}_{2}$ ), thus excluding direct radiative forcing due to changes in the masses of radiatively active species. We explore the dependence of climate on atmospheric mass using a 3D GCM with aquaplanet simulations (introduced in section 2). This modeling study with aquaplanet idealization reduces the complexity of surface conditions and orography but retains the key dynamics and physics of the atmosphere, a step in the model hierarchy connecting studies with simplified GCMs (e.g., Chemke et al. 2016; CK17) and comprehensive and realistic GCM simulations (e.g., Wolf and Toon 2013; Charnay et al. 2013). Our simulation results show an intriguing, nonmonotonic dependence of climate on atmospheric mass that has not been reported before (section 3). We elaborate a convection-circulation-cloud coupled feedback that causes this nonmonotonic dependence in section 4 . Section 5 shows that the proposed feedback is effective only over a certain regime of SP changes and is ineffective outside (i.e., feedback saturation). Section 6 presents sensitivity tests on the robustness of results. The conclusions and discussion are in section 7 .

\section{Model description and experimental design}

The numerical simulations are carried out by the Community Atmosphere Model, version 3.0 (CAM3) (Collins et al. 2004, 2006). The radiative transfer model in CAM3 is based on Ramanathan and Downey (1986) and Briegleb (1992) with the updates described in Collins et al. (2004). Clouds are parameterized into three categories: marine stratus clouds, layered clouds, and convective clouds. All simulations have 26 vertical levels at the resolution of T42 $\left(2.8^{\circ} \times 2.8^{\circ}\right)$. We perform aquaplanet simulations with a slab ocean of $50-\mathrm{m}$ depth. A prescribed meridional heat flux is applied to the slab ocean (Briegleb et al. 2004), mimicking the heat transport by ocean circulations. The insolation is set to $1365 \mathrm{~W} \mathrm{~m}^{-2}$ with zero obliquity. Thus, the seasonal cycle is omitted, while the diurnal cycle retains. The $\mathrm{CO}_{2}$ concentration is set to 0.36 mbar. Other radiatively active gases include $\mathrm{CH}_{4}(800 \mu$ bar $), \mathrm{N}_{2} \mathrm{O}$ (270 $\mu$ bar), and $\mathrm{O}_{3}$ [the vertical profile in Dütsch (1978)]. Each simulation is run for 60 years. It takes less than 50 years to reach the equilibrium state, and outputs of the last 10 years are analyzed. Taking advantage of the hemispheric symmetry, for most simulations, we flip the results in the Southern Hemisphere to the Northern Hemisphere by applying a mirror transform and show figures for the Northern Hemisphere only. We also use the $\sigma$ coordinate (the vertical coordinate of pressure normalized by SP), and all the presented variables are rescaled following Thomson and Vallis (2019).

In the simulations, we change the atmospheric mass by changing the background surface pressure. The SP of the current climate is set to $1000 \mathrm{hPa}$ (1 bar), and a series of experiments are performed in which SP varies from 0.5 to 2.4 bar with all other parameters and setting held constant. We change SP by changing the masses of $\mathrm{N}_{2}$ and $\mathrm{O}_{2}$ proportionally (with the mass ratio of the present-day atmosphere), while keeping the masses of the radiatively active trace species unchanged (except in the sensitivity tests of $\mathrm{SG}_{\mathrm{co} 2}$ ). Atmospheric water vapor is calculated by the internal model physics. Four groups of mechanism-denial experiments (Table 1) are designed to examine potentially relevant processes. In the default group (DG), on which our main analyses are based, the ice-albedo feedback is excluded by not allowing the formation of sea ice. In the sensitivity group $\mathrm{SG}_{\text {ice }}$, the ice-albedo feedback is included by allowing the formation of sea ice. The sensitivity group $\mathrm{SG}_{\mathrm{co} 2}$ is the same as $\mathrm{SG}_{\text {ice }}$, except the volume mixing ratio of $\mathrm{CO}_{2}$ is fixed to 360 ppmv; thus, changing SP also changes the $\mathrm{CO}_{2}$ mass. The sensitivity group $\mathrm{SG}_{\mathrm{cld}}$ is the same as DG, except we turn off the cloud radiative effect by making clouds transparent to radiation.

\section{Dependence of climate on atmospheric mass}

We first examine the dependence of the global-mean surface temperature $\left(\overline{T_{s}}\right.$, where the overbar denotes global average) on SP. With other factors (e.g., convection and atmospheric heat capacity, which are discussed later) remaining unchanged, an increased SP leads to a positive radiative forcing due to the 

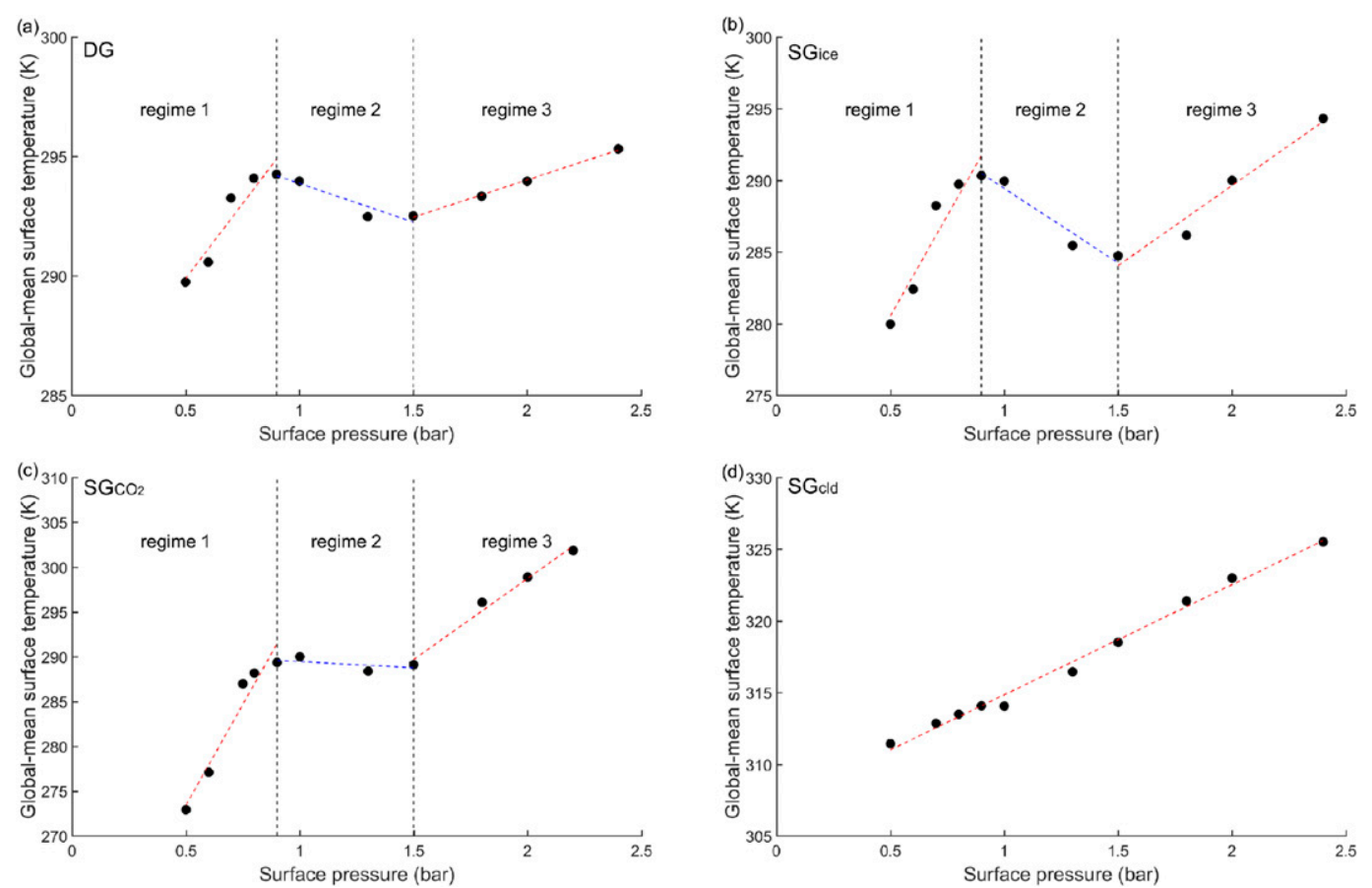

FIG. 1. Global mean surface temperatures $\left(\overline{T_{s}}\right)$ as functions of SP for experimental groups (a) DG, (b) $\mathrm{SG}_{\text {ice }}$, (c) $\mathrm{SG}_{\mathrm{co} 2}$, and (d) $\mathrm{SG}_{\mathrm{cld}}$. The colored dashed lines are the regression lines for the three regimes. Note that the $y$ axis of each panel is different. The values of $\overline{T_{s}}$ in (a) are higher than those in (b) and (c) because sea ice formation is not allowed in DG. The values of $\overline{T_{s}}$ in (d) are higher than those in (a)-(c) because the cloud radiative effect is excluded from $\mathrm{SG}_{\mathrm{cld}}$.

pressure broadening effect on greenhouse gases. Thus, it is expected that $\overline{T_{s}}$ increases with increases in SP, as previous studies have suggested (e.g., Goldblatt et al. 2009; Charnay et al. 2013; Chemke et al. 2016; Hu and Boos 2017; Nie et al. 2019). Interestingly, the experiments in DG show a nonmonotonic dependence of $\overline{T_{s}}$ on SP (Fig. 1a). When SP is between 0.5 and 0.9 bar (regime 1 ) and between 1.5 and 2.4 bar (regime $3), \overline{T_{s}}$ is proportional to SP, although with different slopes. However, over the range from 0.9 to 1.5 bar (regime 2), $\overline{T_{s}}$ is inversely proportional to SP. The inverse proportionality between $\overline{T_{s}}$ and SP in regime 2 is intriguing. In the current climate, given a climate forcing of $1 \mathrm{~W} \mathrm{~m}^{-2}$, there is a corresponding warming of $\sim 0.4 \mathrm{~K}$ (i.e., a climate sensitivity parameter of $2.3 \mathrm{~W} \mathrm{~m}^{-2} \mathrm{~K}^{-1}$; Gregory and Andrews 2016). If we view the radiative forcing due to a SP change as a climate forcing and other processes as climate feedbacks ( $\mathrm{Hu}$ and Boos 2017), the results imply that in regime 2 , the sum of climate feedbacks induces strong radiative cooling that overcomes the positive radiative forcing caused by the increase in SP, leading to a decrease in $\overline{T_{s}}$.

The nonmonotonic dependence of $\overline{T_{s}}$ on SP is also present in $\mathrm{SG}_{\text {ice }}$ and $\mathrm{SG}_{\mathrm{co} 2}$ (Figs. 1b,c). The ice-albedo feedback is a positive climate feedback: a warmer ocean surface decreases the sea ice coverage and thus the planetary albedo, leading to further positive radiative forcing. Including the ice-albedo feedback in $\mathrm{SG}_{\text {ice }}$ does not remove this nonmonotonic dependence but rather amplifies the slopes of $\overline{T_{s}}$ as functions of $\mathrm{SP}$ in all three regimes (Fig. 1b). The nonmonotonic $\overline{T_{s}}-\mathrm{SP}$ dependence is largely independent of greenhouse gasinduced climate change. Experiments in $\mathrm{SG}_{\mathrm{co} 2}$ consider a scenario in which the absolute mass of $\mathrm{CO}_{2}$ proportionally changes with SP. The greenhouse gas-induced change in $\overline{T_{s}}$ approximately superimposes upon the SP-induced change (Fig. 1c). The cooling of $\overline{T_{s}}$ in regime 2 shown in Fig. 1a is largely canceled out by greenhouse gas-induced warming, leading to the nearly flat slop of $\overline{T_{s}}$ (Fig. 1c). In $\mathrm{SG}_{\mathrm{co} 2}$, the slopes of $\overline{T_{s}}$ as functions of $\mathrm{SP}$ in regimes 1 and 3 are also larger than the slopes in DG. Thus, the ice-albedo effect and changes of $\mathrm{CO}_{2}$ are not responsible for the nonmonotonic $\overline{T_{s}}-\mathrm{SP}$ dependence.

It turns out that the cloud radiative effect plays a key role in shaping the $\overline{T_{s}}-\mathrm{SP}$ dependence. The global mean CRE at the top of the atmosphere in DG shows three regimes (Fig. 2) that effectively match the results in Fig. 1a. The amplitude of the CRE variation is significant, at least insomuch that it can contribute substantially to the variation in $\overline{T_{s}}$. For example, as SP increases from 1.0 to $1.5 \mathrm{bar}$, the CRE introduces a forcing of $-2.6 \mathrm{~W} \mathrm{~m}^{-2}$ corresponding to $-1.1 \mathrm{~K}$ of cooling with a climate sensitivity parameter of $2.3 \mathrm{~W} \mathrm{~m}^{-2} \mathrm{~K}^{-1}$ (Gregory and Andrews 2016), compared with the $-1.5 \mathrm{~K}$ of cooling obtained from the simulations. The essential role of the CRE is further confirmed by sensitivity experiments in which the CRE is turned off $\left(\mathrm{SG}_{\mathrm{cld}}\right.$; Fig. 1d). Without the CRE, $\overline{T_{s}}$ displays a nearly linear dependence on SP, and the nonmonotonic $\overline{T_{s}}-\mathrm{SP}$ dependence in the other experiments disappears. 


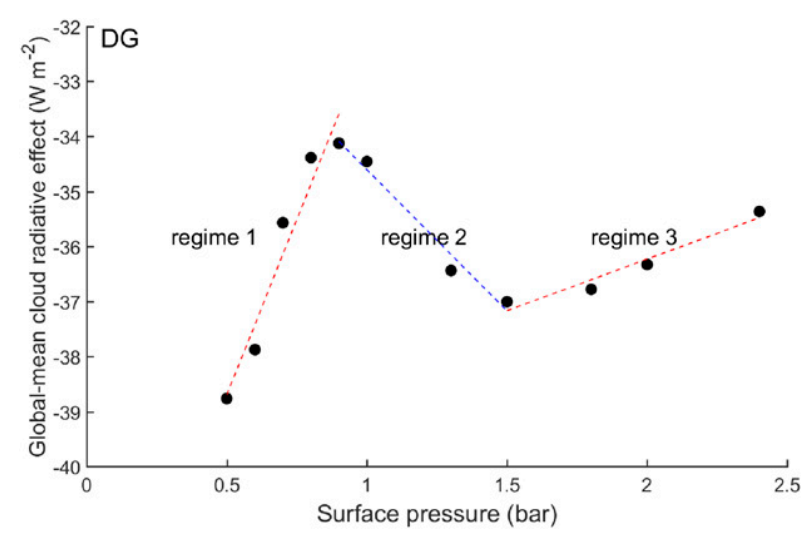

FIG. 2. The global mean cloud radiative effect at the top of the atmosphere as a function of SP in DG.

\section{A convection-circulation-cloud coupled feedback}

The formation of clouds sensitively depends on environmental conditions. In this section, we elaborate the responses of atmospheric thermodynamics and dynamics to SP changes in regime 2 , and link them to the cloud changes. For simplicity, we mainly compare two representative cases in regime 2 : the 1.0- and 1.5-bar cases in DG.

\section{a. Tropical convection}

We first examine the zonal mean temperature distribution in the 1.0-bar case (black contour in Fig. 3a), which shows a typical equator-to-pole temperature gradient similar to that of the present-day climate. The tropopause level, defined as the layer where the vertical lapse rate is less than $2 \mathrm{~K} \mathrm{~km}^{-1}$, decreases from $125 \mathrm{hPa}$ in the tropics to $225 \mathrm{hPa}$ in the polar region. As SP increases to 1.5 bar, $\overline{T_{s}}$ decreases by $1.5 \mathrm{~K}$, with larger cooling at high latitudes $(-4.2 \mathrm{~K}$ in the polar region compared with less than $-1 \mathrm{~K}$ in the tropics; Fig. 3b), similar to the polar amplification of the ongoing global warming (Holland and Bitz 2003) but with the opposite sign. In the stratosphere, there is a dipole of temperature anomalies corresponding to weakening of the stratospheric polar vortex, arguably due to the enhanced propagation of planetary waves into the stratosphere associated with upper-troposphere zonal wind changes (Fig. 4) (Holton and Hakim 2012). As SP increases, the tropopause level descent is consistent with CK17, and the tropospheric temperature decreases, particularly in the tropical upper troposphere (color in Fig. 3a).
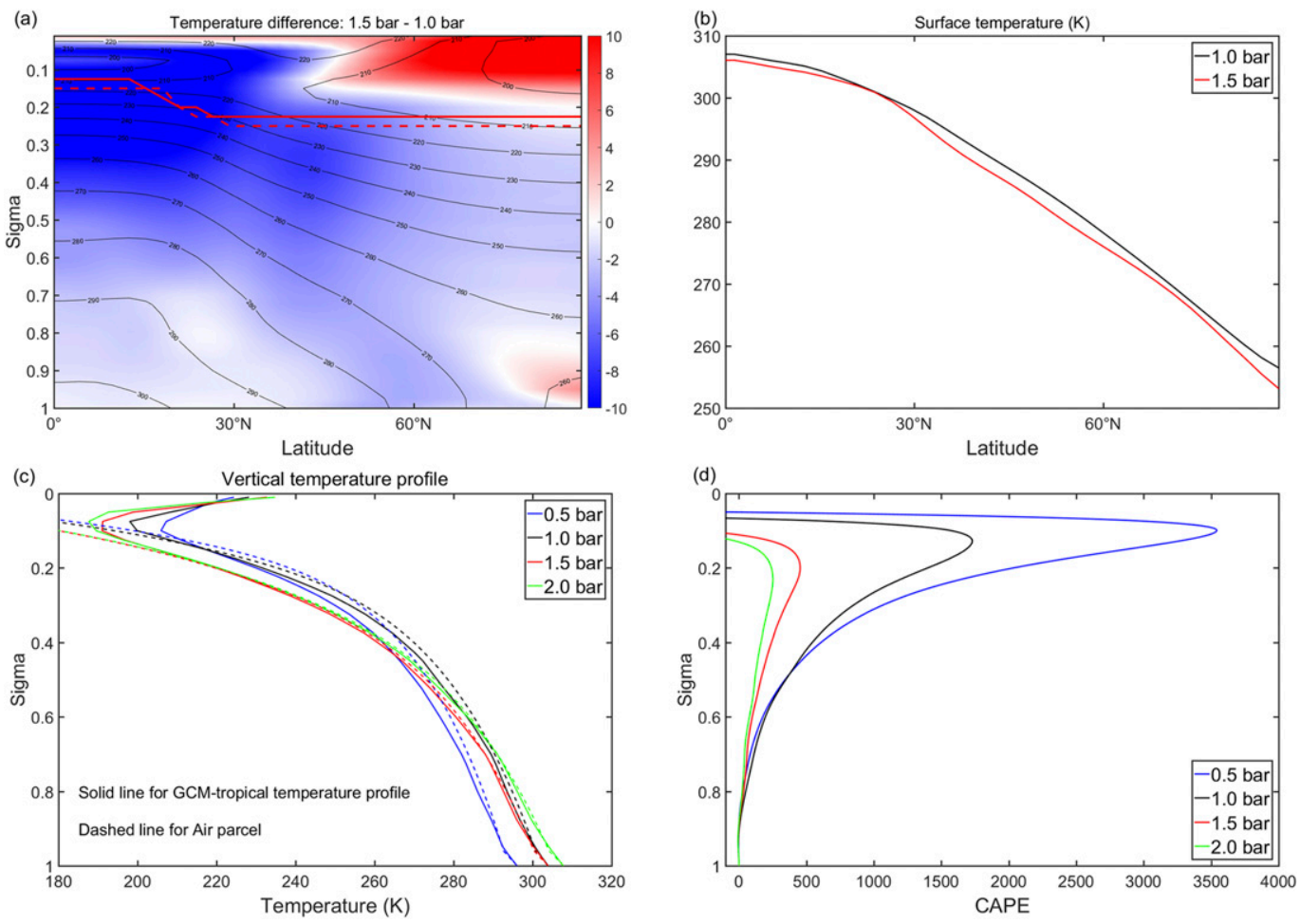

FIG. 3. (a) The zonally averaged temperature in the 1.0-bar case (black contours) and the temperature difference between the 1.5- and 1.0-bar cases (color). The red solid and dashed lines indicate the tropopause level in the 1.0- and 1.5-bar cases, respectively. (b) The zonally averaged surface temperature. (c) The solid lines are the simulated temperature profiles averaged between $10^{\circ} \mathrm{S}$ and $10^{\circ} \mathrm{N}$. The dashed lines are the temperature profiles for a lifted surface air parcel with surface environmental conditions following the moist adiabatic process. (d) Convective available potential energy integrated from the surface to certain sigma levels. The peak level is the convective neutrality level near the tropopause, and the peak value is the conventional CAPE. 

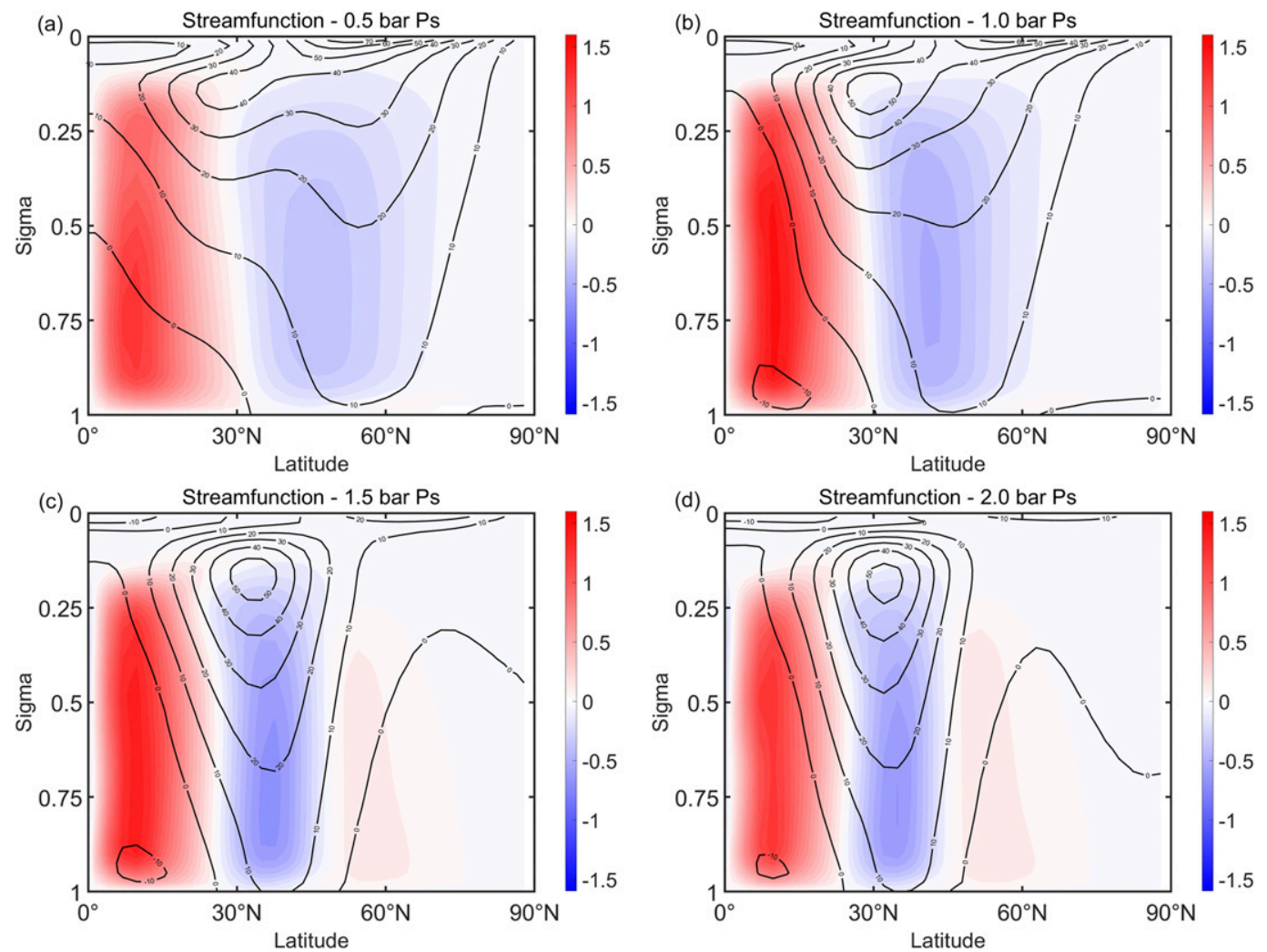

FIG. 4. The mass streamfunction (color shading; $10^{11} \mathrm{~kg} \mathrm{~s}^{-1}$ per 1 bar of SP) and zonal winds (black contours; $\mathrm{m} \mathrm{s}^{-1}$ ) in the (a) 0.5-, (b) 1.0-, (c) 1.5-, and (d) 2.0-bar cases.

The largest signal of the temperature response-the cold anomaly in the tropical upper troposphere (e.g., $-13 \mathrm{~K}$ on the $0.225 \sigma$ level; Fig. 3a) — can be explained by the responses of tropical moist convection. Deep and vigorous convection maintains the tropics in a convective quasi equilibrium and regulates the temperature profiles to be close to moist adiabatic temperature profiles (Emanuel et al. 1994). Changes in SP lead to changes in moist adiabatic temperature profiles (Goldblatt et al. 2009; Thomson and Vallis 2019; Nie et al. 2019). With fixed temperature and relative humidity, increases in SP do not increase the vapor partial pressure because the saturation vapor pressure depends only on temperature. However, increases in SP decrease the mixing ratio of water vapor, thus increasing the moist adiabatic lapse rate. In other words, for a lifting air parcel, increasing SP does not increase the release of latent heat but increases the heat capacity of the parcel by adding more dry air, thus weakening the latent heating effect of water vapor. Calculations of the moist adiabatic temperature profiles confirm the above argument (Fig. 3c). As SP increases, the tropical temperature profiles (solid lines) closely follow the changes in moist adiabatic temperature profiles (dashed lines). The temperature differences between the moist adiabatic lifting parcel and the environment measure the convective available potential energy (CAPE) of moist convection. Due to the weakening of the latent heat effect, the CAPE decreases as SP increases (Fig. 3d), consistent with CK17. In our simulations and many previous studies, convective parameterizations and their parameters (e.g., the CAPE consumption time scale; Collins et al. 2004) are independent on SP. Although some cloud-resolving simulations (e.g., $\mathrm{Hu}$ and Boos 2017) did not find dramatic behavior changes of convection with SP changes, the validity of such approximation needs further examination, especially for simulations of exoplanet atmosphere with large SP ranges and different compositions (e.g., Ding and Pierrehumbert 2016).

In the extratropics, without the strong constraint of deep convection, the temperature structure is determined by several factors, including local convection, radiation, heat transport, and dynamics (e.g., through the thermal wind balance). The cold anomalies in the tropical free troposphere weaken the polarward transport of energy (heat and moisture) by mean circulations and eddies, leading to tropospheric temperature decreases in the extratropics (Fig. 3a). Besides, the increase in atmospheric mass increases the heat capacity, which weakens the radiative forcing vertical dependence and reduces the static stability (Chemke et al. 2016). While both processes may contribute to the free-tropospheric cold anomalies in the subtropics, the latter may be more relevant for the middle and high latitudes CK17.

\section{b. Circulation}

The atmospheric circulation undergoes significant adjustments when SP changes (Figs. 4 and 5). We focus on the comparison between the 1.0- and 1.5-bar cases (Figs. 4b,c and 5b,c) in this 

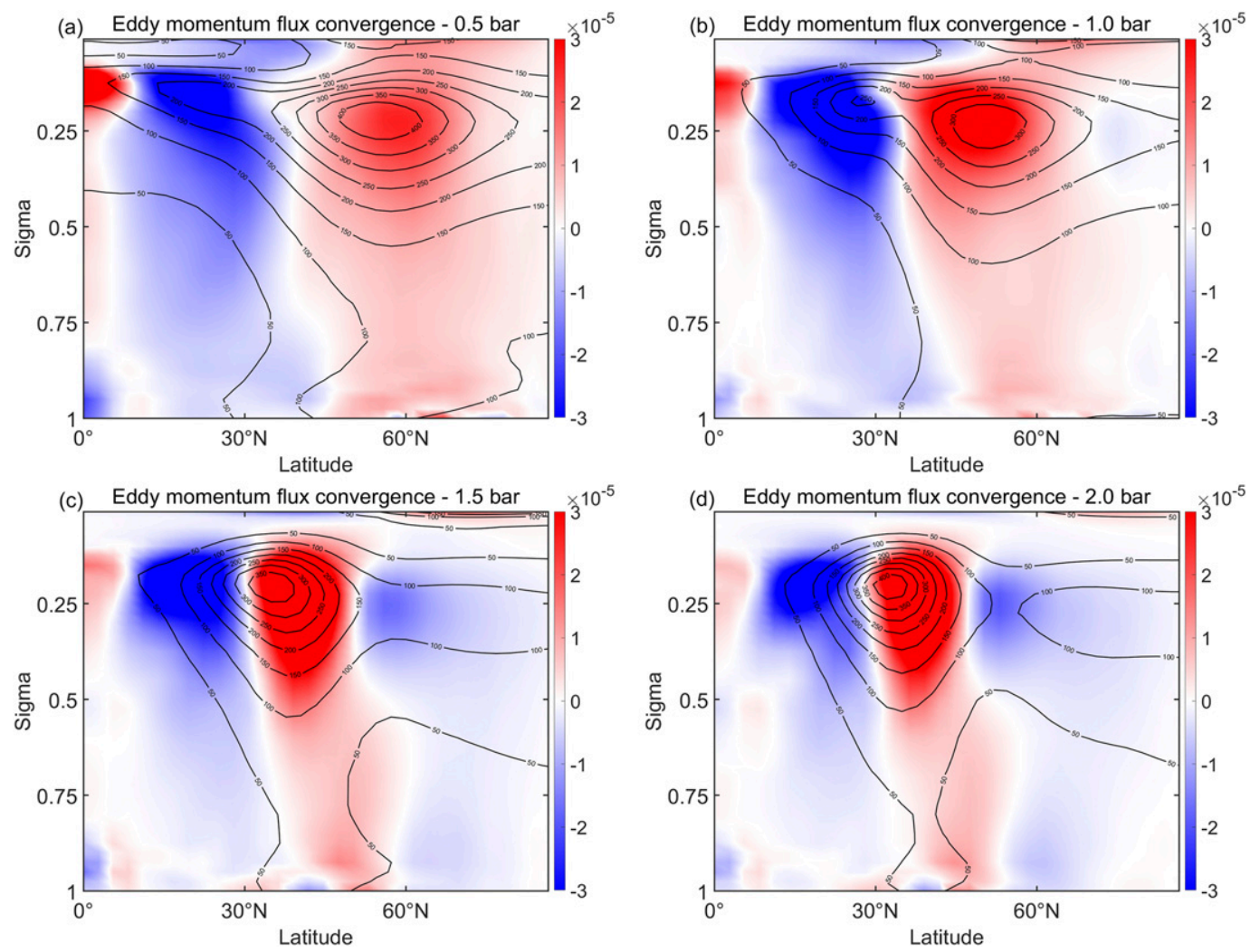

FIG. 5. The eddy momentum flux convergence $\left(-\partial_{y} \overline{u^{\prime} v^{\prime}} ; \mathrm{m} \mathrm{s}^{-2}\right.$; red indicates convergence, while blue indicates divergence) and the storm track $\left(\overline{v^{\prime} v^{\prime}}\right.$; black contours; $\left.\mathrm{m}^{2} \mathrm{~s}^{-2}\right)$ in the (a) 0.5-, (b) 1.0-, (c) 1.5-, and (d) 2.0-bar cases.

section, and discuss the 0.5- and 2.0-bar cases (Figs. 4a,d and $5 \mathrm{a}, \mathrm{d})$ in section 5. In the tropics, the width of the Hadley cell narrows as SP increases (Figs. 4b,c). It is perhaps convenient to understand the contraction of the Hadley cell as the opposite to the widening of the Hadley cell of the undergoing global warming (Frierson et al. 2007; Hu et al. 2018). Based on the axisymmetric thermal-driven theory of the Hadley circulation (Held and Hou 1980), the descent of the tropical tropopause and the decreases of the meridional temperature gradient (Fig. 3a) can lead to narrowing of the Hadley cell (CK17). Another perspective states that the width of the Hadley cell is determined by the polarward extent to which baroclinic eddies become unstable (Held 2000). In our simulations, the cold anomalies decrease the static stability in the subtropics and middle latitudes (Fig. 3a) and enhance the baroclinicity therein, which may also contribute to the contraction of the Hadley cell.

In the extratropics, zonal westerly jets show an abrupt regime transition. In the 1.0-bar case, there is a subtropical jet (STJ) and a relatively weak eddy-driven jet (EDJ) in the middle latitudes (Fig. 4b). The STJ is mainly due to the planetary angular momentum transport by the thermally driven Hadley circulation (Held and Hou 1980). In contrast, the EDJ is located inside the Ferrel cell and maintained by baroclinic eddy momentum flux convergence (Fig. 5b) (Held 1975). The two jets merge into a single jet as SP increases to 1.5 bar (Fig. 5c). This merged jet has mixed features of both the STJ and the EDJ: on its equatorward flank, the jet is maintained by the transport of angular momentum by mean circulations and is vertically more baroclinic than barotropic, while on its polarward flank, the jet is maintained by eddy momentum convergence (Fig. 5c) and is vertically more barotropic than baroclinic.

The transition from separate jets to a merged jet is due to the strengthening and equatorward shift of the midlatitude EDJ. As SP increases, in association with the increases in the moist adiabatic lapse rate in the tropics, the midlatitude tropospheric temperature decreases faster than the surface temperature (Fig. 3). As a result, the static stability decreases, and the midlatitude baroclinicity increases. One may use the maximum Eady growth rate (b) to quantify the baroclinicity (Hoskins and Valdes 1990; Brayshaw et al. 2008):

$$
b=-\frac{0.31 g}{N \theta_{0}} \frac{\partial \bar{\theta}}{\partial y}
$$

where $\theta$ is the potential temperature and $N$ is the Brunt-Väisälä frequency (a measure of the static stability). Calculations of the $b$ confirm that baroclinic zone shifts equatorward and that the baroclinicity increases as SP increases (Fig. 6). This increased baroclinicity strengthens the baroclinic eddies and the EDJ, as seen from the enhancement of the storm track and eddy momentum flux convergence (Fig. 5). The equatorward shift of the baroclinic zone also pulls the storm track and EDJ equatorward and merges the EDJ with the STJ. The Ferrel cell, which is driven by eddy momentum and temperature flux convergence, 


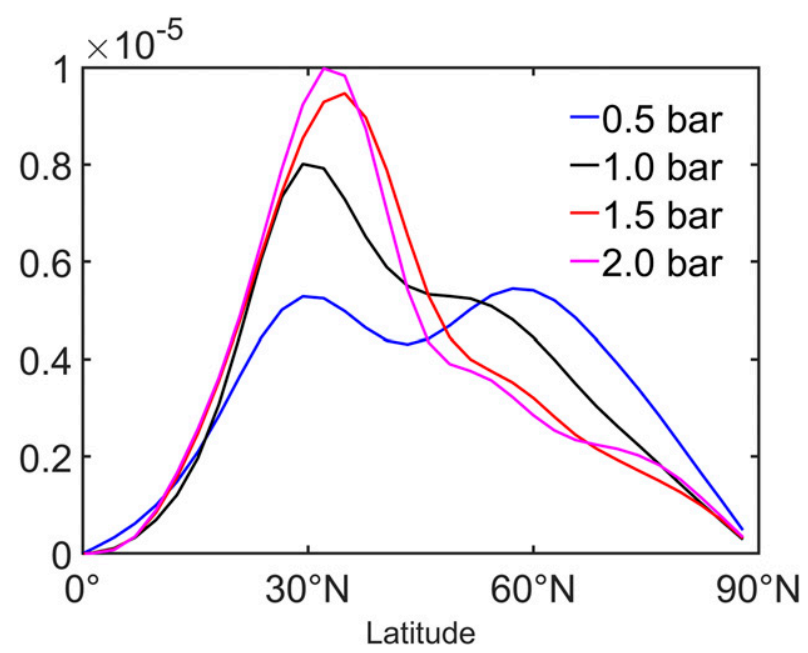

FIG. 6. Maximum Eady growth rate $\left(b ; \mathrm{s}^{-1}\right)$ vertically averaged between the 0.75 and $0.25 \sigma$ levels.

shifts equatorward with the EDJ and is slightly strengthened (Fig. 4). In the 1.5 bar case, a polar cell emerges corresponding to the divergence of the eddy momentum flux to the north of the Ferrel cell at $\sim 60^{\circ} \mathrm{N}$ (i.e., by the momentum balance of $f \bar{v}=\partial_{y} \overline{u^{\prime} v^{\prime}}$; Figs. 4c and 5c). The descending branch of the polar cell in the polar region warms the troposphere adiabatically and increases the static stability therein (Fig. 3a).

Figure 7 summarizes the responses of the atmospheric circulation to changes in SP: the contraction of the Hadley cell and the Ferrel cell, the enhancement of the storm track (in regime 2), and the merging of jets. CK17 varied SP from 0.5 to 100 bar in a simple GCM. They found that increases of SP resulted in contraction of the Hadley cell and emergence of multiple meridional circulation cells in the extratropics, consistent with the results here. Differently, they found that increases of SP led to weakening of the extratropical circulation and eddies, due to the decrease in the meridional temperature gradient. The results here show strengthening of the extratropical circulation and eddies as SP increases from 1.0 to 1.5 bar, because the effect of decreases in the static stability overcomes the effect of decreases in the meridional temperature gradient. Moreover, the stronger cooling in the higher latitudes (Fig. 3a) weakens the decrease of the meridional temperature gradient in middle latitudes. The discrepancy may be largely due to the exclusion of CRE in CK17. Besides, regime 2 was not explicitly examined in CK17: their SP cases are $0.5,1,3$ bar, etc. Nevertheless, it is likely that as SP further increases in regime 3 , the results of the aquaplanet simulations will be consistent with those in CK17. The transition of flow regime due to SP changes may be compared with the behaviors of jet in the current climate. In observations, both states of jets are seen in different seasons or longitude sectors (Eichelberger and Hartmann 2007; Li and Wettstein 2012; Yuval et al. 2018). For example, there are double jets in the North Atlantic winter and in the Southern Hemisphere winter, analogous to the lowSP cases, and there is a single merged jet in the North Pacific winter and in the Southern Hemisphere summer, analogous to

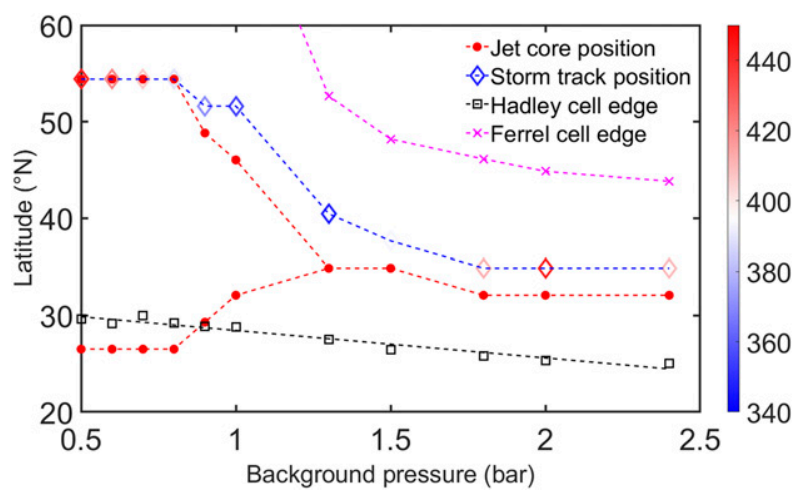

FIG. 7. The red dots indicate the latitudes of jet cores, defined as the maximum latitude of zonal winds averaged between the 0.25 and $0.1 \sigma$ levels. The diamonds indicate the latitudes of stormtrack maxima, with the color denoting the maximum value. The black squares indicate the polarward edge of the Hadley cell, defined as the latitude of the first zero-streamfunction contour on the $0.5 \sigma$ level. The magenta stars indicate the poleward edge of the Ferrel cell, defined as the latitude of the second zero-streamfunction contour on the $0.5 \sigma$ level. To improve visibility, the dashed lines connect the corresponding markers, the exception being the black dashed line, which is the line of the Hadley cell edge obtained by linear regression.

the high-SP cases. Many work have studied the interactions of the jets in the current climate (e.g., Nakamura and Sampe 2002; Kim and Lee 2004; Lee and Kim 2003; Son and Lee 2005; Brayshaw et al. 2008; O'Rourke and Vallis 2013), and it may help us understand the sharp transition of flow regime in our simulations. The superimposition of the two jets can modify the background flow structure, which further alters the wave generation, wave propagation, and its associated momentum flux transport, in a way that tends to merge two jets. For example, Lee and Kim (2003) and Eichelberger and Hartmann (2007) found that the approaching of two jets traps the wave near them and prevent leakage of momentum transport. Besides, the effect of latent heating may also contribute to the merging of jets (Son and Lee 2005). Our results are also consistent with the work of Lachmy and Harnik (2016), which founds the regime transition from the subtropical jet to the merged jet is associated with increases of extratropical eddy kinetic energy.

\section{c. Cloud}

Now, we examine the responses of clouds (Fig. 8), which play a key role in the nonmonotonic $\overline{T_{s}}-\mathrm{SP}$ dependence (section 3), and we link those responses to the responses of circulations. In the 1.0 bar case (Fig. 8a), the tropical deep clouds reach the tropopause. In the subtropics, the strong subsidence of the Hadley cell inhibits convection, and clouds remain within the lower troposphere. In the middle latitudes, a cloud belt extends throughout the troposphere, corresponding to synoptic disturbances in storm tracks. In the polar region, there are abundant low-level clouds near the surface and high clouds due to the cold temperature there. Corresponding to the cloud distribution, reflection of insolation leads to strong shortwave CRE cooling in the tropics and middle latitudes 

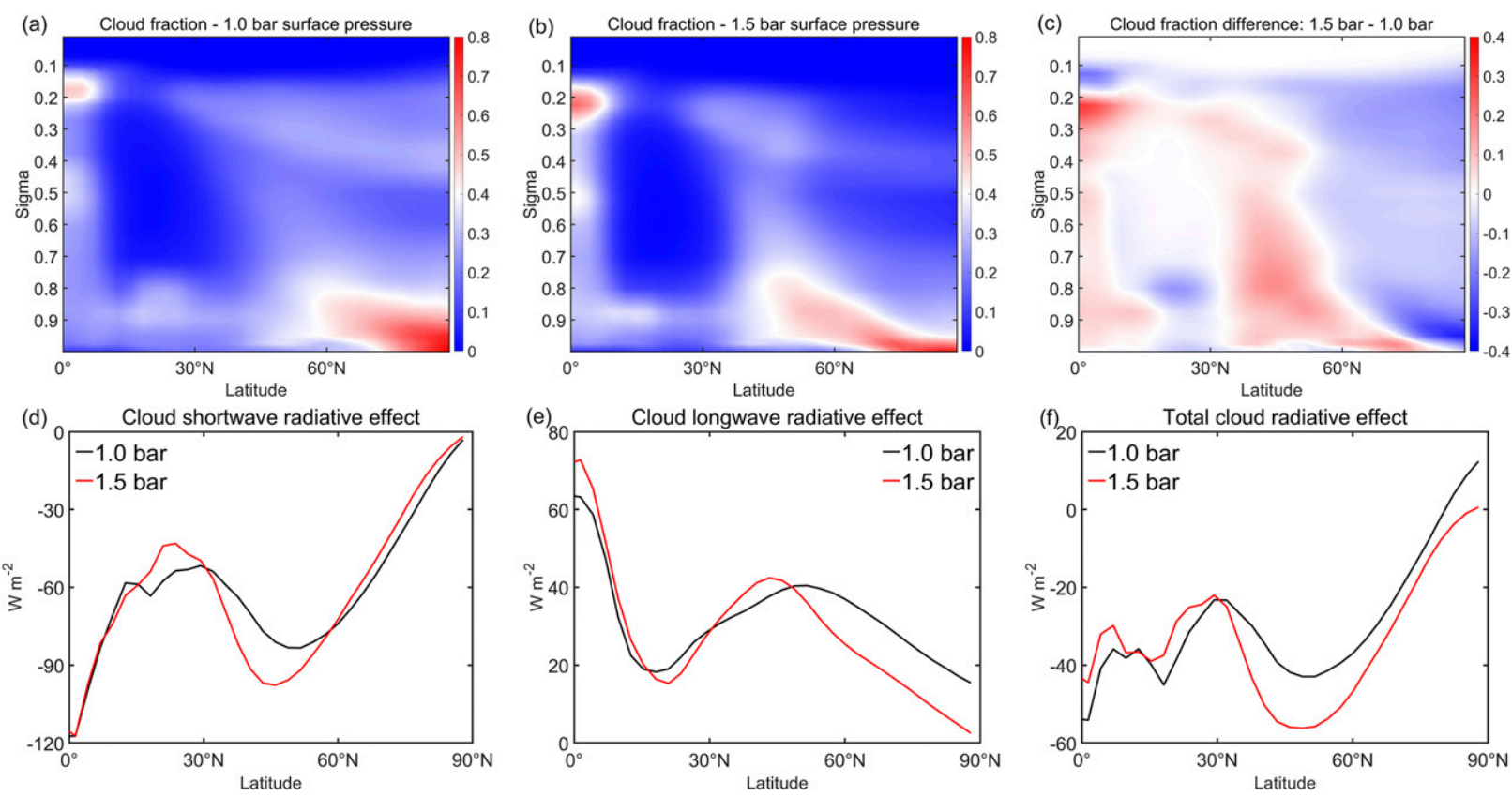

FIG. 8. (a)-(c) The zonal mean cloud fractions in the (a) 1.0-bar case and (b) 1.5-bar case and (c) their differences. (d) The shortwave cloud radiative effect, (e) the longwave cloud radiative effect, and (f) the total cloud radiative effect.

(Fig. 8d). At high latitudes, the shortwave CRE approaches zero due to the weak insolation therein. On the other hand, high clouds have a strong greenhouse gas effect that induces a positive longwave CRE (Fig. 8e). The net CRE is negative at most latitudes but is slightly positive in the polar region (Fig. 8f). The globally averaged net CRE is $-34.5 \mathrm{~W} \mathrm{~m}^{-2}$ $\left(-68.0 \mathrm{~W} \mathrm{~m}^{-2}\right.$ in shortwave and $33.5 \mathrm{~W} \mathrm{~m}^{-2}$ in longwave). For comparison, observational estimations of the current climate show a globally averaged net CRE of $-21.1 \mathrm{~W} \mathrm{~m}^{-2}$ $\left(-47.5 \mathrm{~W} \mathrm{~m}^{-2}\right.$ in shortwave and $26.4 \mathrm{~W} \mathrm{~m}^{-2}$ in longwave; Stephens et al. 2012), although one should not expect the results of these idealized aquaplanet simulations to match the observations well. This discrepancy is mostly due to the aquaplanet setting having a relatively low surface albedo.

The responses of the cloud fraction as SP increases to $1.5 \mathrm{bar}$ are shown in Figs. $8 \mathrm{~b}$ and $8 \mathrm{c}$. The fraction of tropical deep clouds increases, while that of subtropical low clouds decreases; these responses are consistent with the changes in the ascending and descending branches of the meridional mean circulation (Figs. 4b,c). The midlatitude cloud belt is enhanced and shifts equatorward, consistent with the equatorward shift of the storm track (Figs. 5b,c). In the polar region, the cloud fraction decreases at all levels, consistent with the increased static stability associated with the subsidence of the polar cell (Figs. 4b,c). The responses of clouds induce positive shortwave radiative forcing in the subtropics and negative radiative forcing in the middle latitudes (Fig. 8d). In the longwave bands, positive radiative forcing occurs in the tropics, while strong negative radiative forcing occurs at mid- to high latitudes (Fig. 8e). The net CRE anomaly is dominated by cooling in the extratropics (Fig. 8f), which is a combined result of the equatorward shift of the midlatitude cloud belt and decreases in polar clouds.
All the responses shown in this section form a convectioncirculation-cloud coupled feedback, leading to climate cooling as SP increases from 1.0 to 1.5 bar. This feedback is summarized in the schematic shown in Fig. 9. In the 1.0-bar case, there is a Hadley cell and a relatively broad Ferrel cell associated with a subtropical jet and an eddy-driven jet, respectively. As SP increases, the moist adiabatic lapse rate and atmospheric heat capacity increases, leading to upper-troposphere cold anomalies in the tropics and middle latitudes. Due to these cold anomalies, the baroclinicity and eddy activity in the subtropics and middle latitudes increase. Thus, the eddy-driven jet is enhanced, shifts equatorward, and merges with the subtropical jet. The midlatitude cloud belt moves equatorward with the eddydriven jet, and the subsidence of the emerged polar cell inhibits the formation of clouds in the polar region. These cloud changes enhance the cloud radiative cooling effect and cool the climate.

\section{Feedback saturation}

The convection-circulation-cloud feedback introduced in the previous section explains both the enhanced cloud radiative cooling effect and the decrease in $\overline{T_{s}}$ throughout regime 2 (0.9-1.5 bar). In this section, we demonstrate that this feedback functions only during the abrupt regime transition from separate jets to a merged jet. Changing the SP in regime 1 (0.5-0.9 bar) or in regime 3 (1.5-2.4 bar) does not lead to significant changes in the jets. As a result, the CRE responds differently.

We compare the results between the 1.0- and 0.5-bar cases and between the 2.0- and 1.5-bar cases to understand the responses in regimes 1 and 3 , respectively. The temperature differences between these two pairs of experiments are shown in Figs. 10a and 10c. In the lower to middle troposphere, 
(a) 1.0 bar case

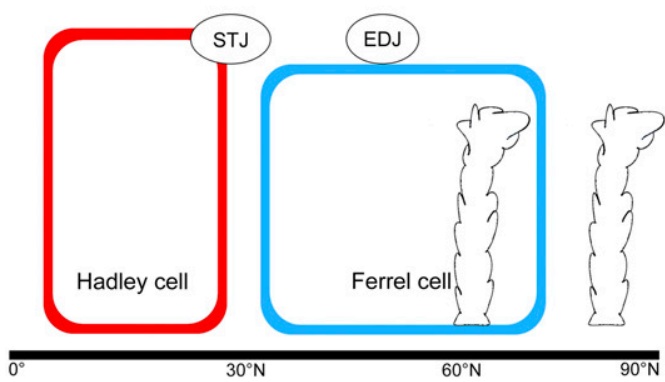

(b) 1.5 bar case

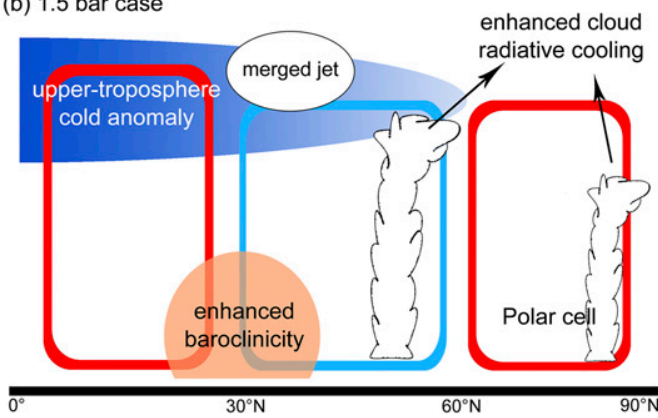

FIG. 9. Schematic of the convection-circulation-cloud coupled feedback. See the text at the end of section 4c for details.

there are positive temperature anomalies associated with surface warming. However, there are significant upper-troposphere cold anomalies in the tropics that extend into the middle latitudes, similar to the case in regime 2. These upper-troposphere cold anomalies lead to narrowing of the Hadley cell (Fig. 4). In regime 1 , as SP increases, the positions of the jet cores show little change, although the STJ is enhanced due to the strengthening of the Hadley cell (Fig. 4). Throughout this regime, the subtropical baroclinicity increases (Fig. 6) due to the cooling of the upper troposphere; however, these increases are not large enough to shift the jet position (Fig. 7). In regime 3, the state of the single merged jet is quite stable, a further increase in SP leads only to a slight equatorward shift of the merged jet (Fig. 8).

The responses of clouds in regimes 1 and 3 (Figs. 10b,d) are consistent with the above temperature and circulation changes. However, the responses of the CRE are different. As SP increases from 0.5 to 1.0 bar, the large increases in the deep cloud fraction in the tropics and middle latitudes induce both shortwave cooling due to the reflectivity of insolation and longwave warming due to longwave absorption, achieving an overall positive net effect (Fig. 11). In high-latitude regions, decreases
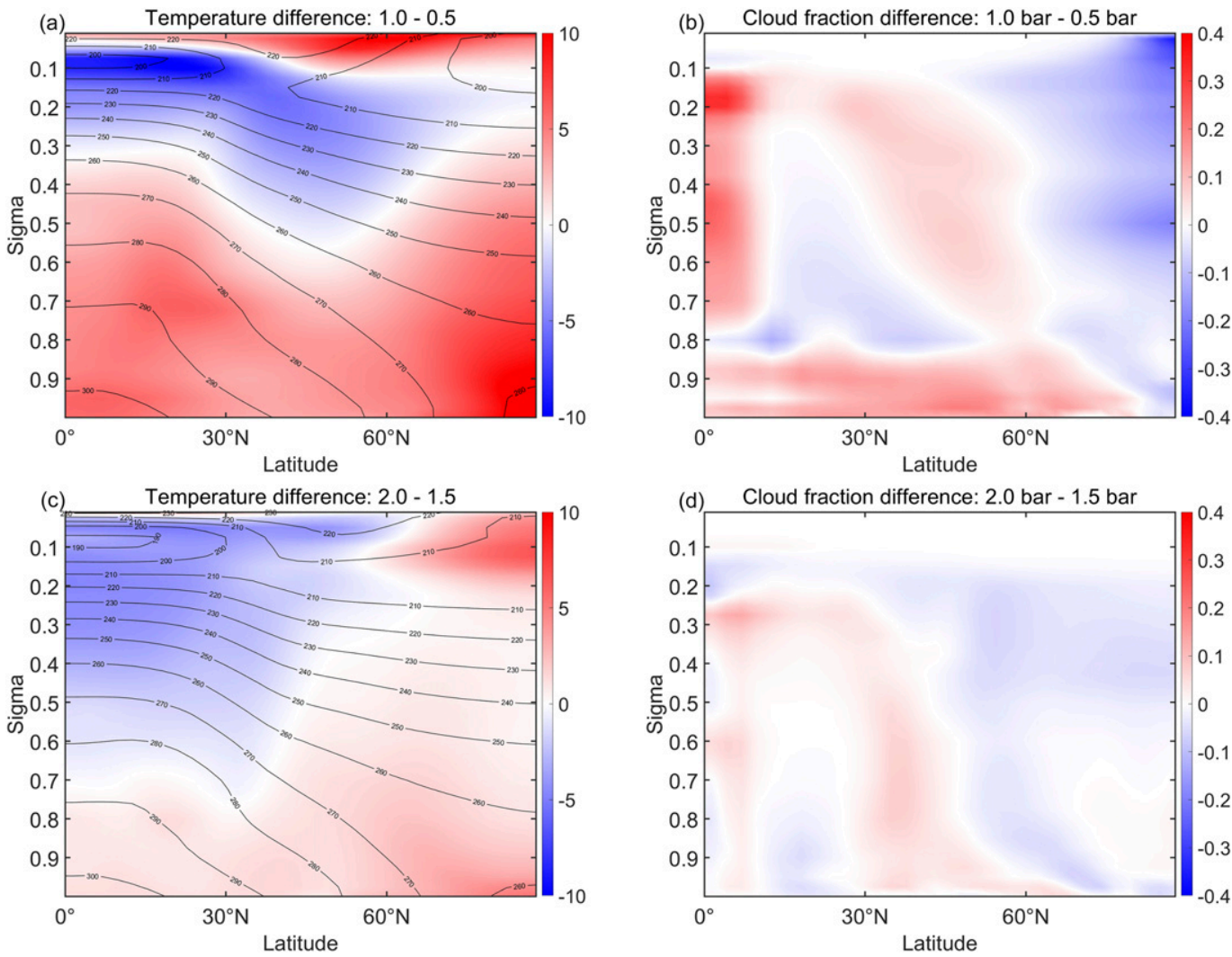

FIG. 10. (a) Temperature differences and (b) cloud fraction differences between the 1.0- and 0.5-bar cases. (c),(d) As in (a) and (b), but for the differences between the 2.0- and 1.5-bar cases. 

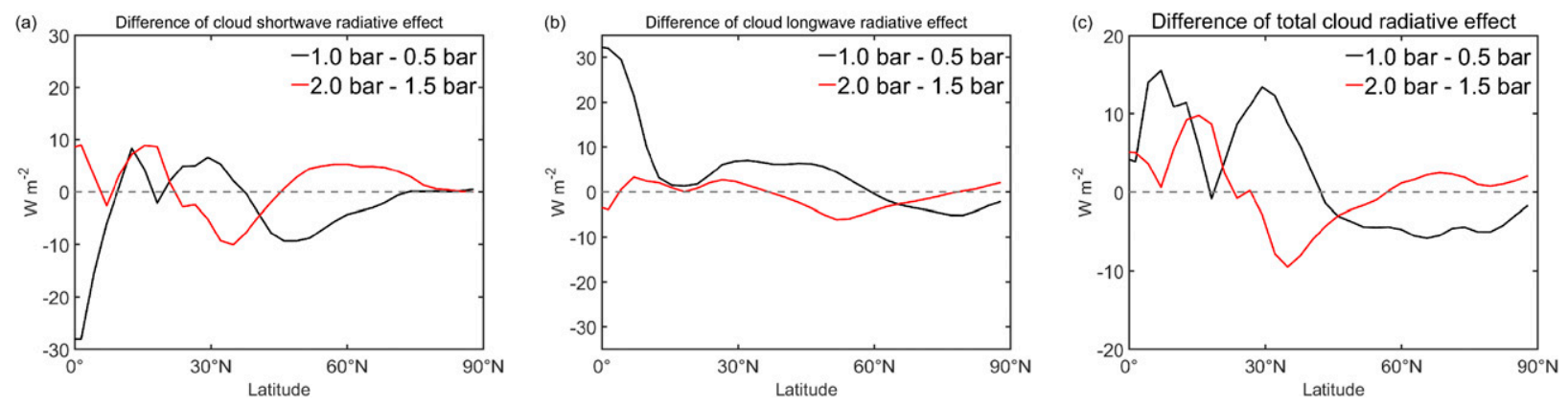

FIG. 11. Differences in the (a) shortwave CRE, (b) longwave CRE, and (c) net CRE between the 1.0- and 0.5-bar cases (black lines) and between the 2.0- and 1.5- bar cases (red lines).

in the cloud fraction lead to radiative cooling. However, the amplitude of this cooling is very weak. The reason for this phenomenon is presumably that the temperature difference between the surface and cloud top in regime 1 is relatively small; thus, the greenhouse gas effect of polar clouds is weak, as is the longwave CRE response. As SP increases from 1.5 to 2.0 bar, the net cloud radiative forcing is positive at low latitudes. In the middle latitudes, the cloud radiative forcing is negative due to the enhanced shortwave reflection (Fig. 11a) associated with increased clouds (Fig. 10d). Averaged over the globe, the net cloud radiative forcing is positive as the SP increases in regime 1 and regime 3 (Fig. 2). Only throughout regime 2 , in which the jets shift abruptly from a separate state to a merged state, are there large cloud responses that induce strong radiative cooling.

\section{Robustness of results}

Climate is a complex system including many feedback mechanisms that are competing with each other. This convectioncirculation-cloud coupled feedback presented above critically depends on the responses of convection, circulation, and clouds to SP changes. The robustness of those responses is examined with additional tests here. Section 6 a presents simulations with the seasonal cycle included to test the robustness on seasonality, and section $6 \mathrm{~b}$ presents simulations with perturbed parameter in cloud parameterizations to test the robustness of cloud responses.

\section{a. Seasonal cycle}

The meridional circulation cells and westerly jets have complex behaviors in different seasons and regional sectors (e.g., Dima and Wallace 2003; Eichelberger and Hartmann 2007; Li and Wettstein 2012). Their responses to the greenhouse gas-induced global warming also differ across seasons and regional sectors (e.g., $\mathrm{Hu}$ et al. 2018; Barnes and Polvani 2013). The seasonal cycle may play roles in the circulation responses to SP changes. We repeat the default group simulations with the seasonal cycle. The simulation results are summarized in Fig. 12. We first observe that the $\overline{T_{s}}-\mathrm{SP}$ dependence still shows three regimes (Fig. 12a), although the slope in each regime slightly differs from those in Fig. 1a. With the seasonal cycle included, both the thermodynamical and dynamic fields show seasonal hemispheric asymmetry, as demonstrated in boreal summer (June-August) mean temperature, streamfunction, and zonal winds (the black contours in Figs. 12b-d are for the 1.0-bar case). As expected, the winter hemisphere has lower temperature, stronger and wider Hadley cell, and stronger westerly jet than the summer hemisphere has. The hemispheric asymmetry is weaker than that in the observations (e.g., Hartmann 2015), presumably due to lack of continents in the aquaplanet setting. As SP increases to $1.5 \mathrm{bar}$, both hemispheres show similar responses (the contraction of the Hadley cell, and the narrowing and the equatorward shift of the westerly jet), although the responses in the winter hemisphere are stronger than those in the summer hemisphere (colors in Figs. 12c and 12d). After the annual average, the responses of temperature and circulations to SP changes are similar to the results presented in the previous sections (figures in the online supplementary information).

The above simulation results suggest that the inclusion of the seasonal cycle leads to similar circulation responses, and the convection-circulation-cloud feedback keeps robust. However, the sensitivity test is with caveats. In reality, the inhomogeneity of surface condition (orography and sea surface temperature distribution) induces large seasonal variations of jets with distinct regional features (Li and Wettstein 2012; Yuval et al. 2018), which may be more sensitive on SP changes. A comprehensive examination of the effects of seasonality requires further investigation in future.

\section{b. Cloud parameter perturbation}

There is large uncertainty in the cloud responses to climate change, due to our limited understanding of cloud physics and its inadequate representation in GCMs. While a thorough investigation of cloud parameterization is beyond our scope, here we test the sensitivity of our results on one key parameter in the cloud parameterization. The CAM3.0's cloud parameterization includes three components, the stratus cloud, the convective cloud, and the layered cloud (Collins et al. 2004). The cloud changes in the middle and high latitudes are more relevant in our coupled feedback, and the cloud there is mostly layered cloud, which is parameterized as

$$
C_{c}=\left(\frac{\mathrm{RH}-\mathrm{RH}_{\text {min }}}{1-\mathrm{RH}_{\text {min }}}\right)^{2} .
$$



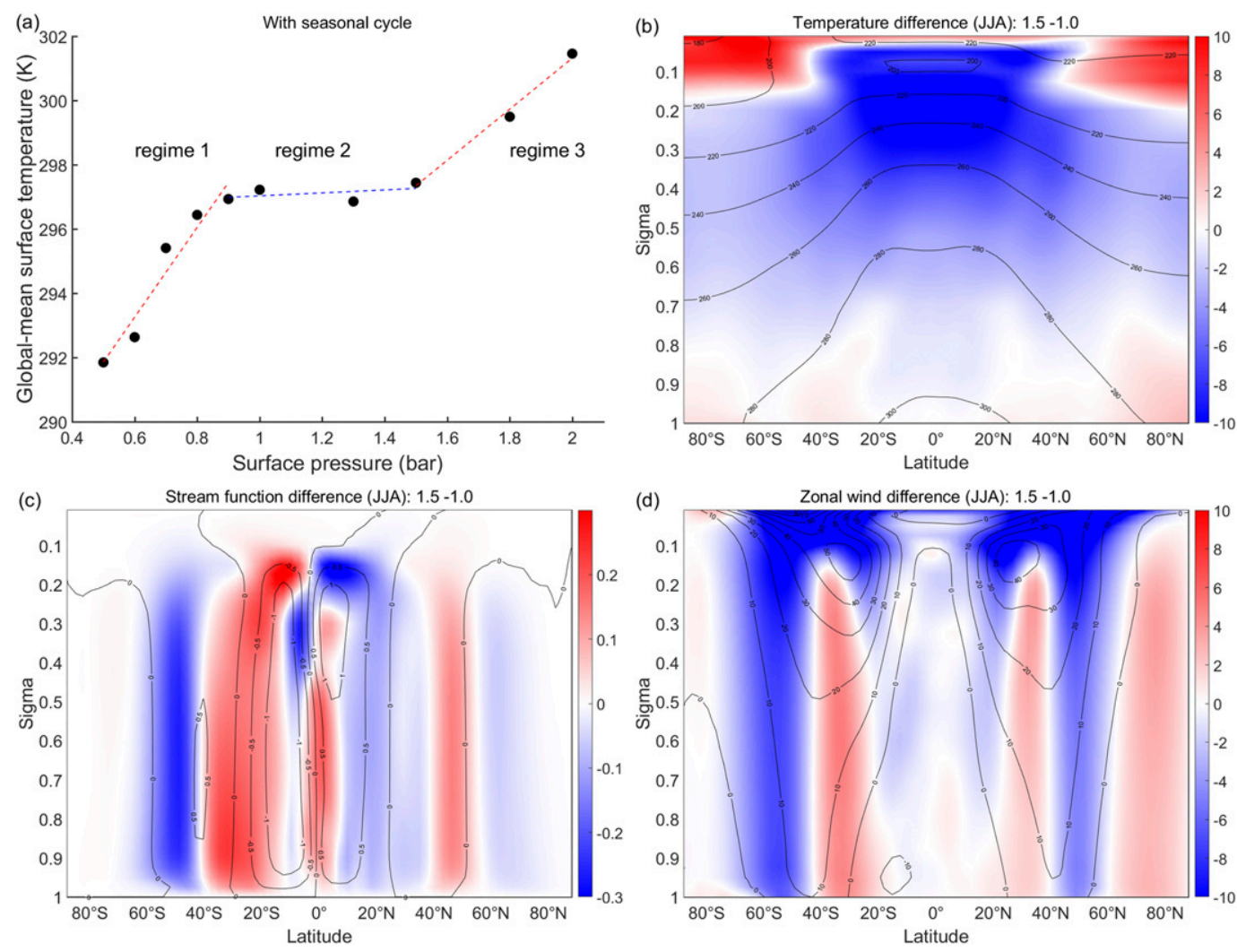

FIG. 12. Results for the simulation group with the seasonal cycle. (a) $\overline{T_{s}}$ as a function of SP. (b)-(d) The June-August (JJA) averaged temperature (K), streamfunction $\left(10^{11} \mathrm{~kg} \mathrm{~s}^{-1}\right)$, and zonal winds $\left(\mathrm{m} \mathrm{s}^{-1}\right)$, respectively. In (b)-(d), the black contours are for the 1.0-bar case, and the color maps are the difference between the 1.5- and 1.0-bar cases.

In the above equation, $\mathrm{RH}$ is the relative humidity, and $\mathrm{RH}_{\mathrm{min}}$ is the threshold parameter, which has different values for low and high clouds $\left(\mathrm{RH}_{\operatorname{minl}}\right.$ and $\left.\mathrm{RH}_{\text {minh }}\right)$. Previous studies screening the sensitivity of CAM on parameter perturbations had identified the key role of $\mathrm{RH}_{\text {min }}$ in controlling cloud amount and the associated CRE (e.g., Jackson et al. 2008; Sanderson 2011; Covey et al. 2013). We repeat the default group simulations with $\mathrm{RH}_{\text {minh }}$ perturbed from its default value of 0.8 to 0.7 and 0.9 .

The results of the two parameter-perturbation simulations are summarized in Fig. 13. The nonmonotonic dependence of $\overline{T_{s}}$ on SP is robust under the parameter perturbation (Fig. 13a). As the $\mathrm{RH}_{\text {minh }}$ parameter increases, the atmospheric $\mathrm{RH}$ increases in most latitudes (Fig. 13b), since it can reach up to a higher value before triggering the layered cloud formation. The exception is in the tropics and lower levels of middle latitudes, where the cloud fraction is mainly determined by the other two cloud types. The increase of $\mathrm{RH}$ leads to the stronger greenhouse gas effect and warms the climate. The climatology of cloud fraction shifts significantly as $\mathrm{RH}_{\text {minh }}$ increases, not only in the middle and high latitudes, but also in the tropics (Fig. 13c). Within each simulation group, the responses of clouds (Fig. 13d) and circulations (supplementary information) to the SP changes are similar to those in DG. These simulations indicate that the nonmonotonic $\overline{T_{s}}-\mathrm{SP}$ dependence passes this parameter perturbation test. We also tested the robustness of our results by repeating the DG simulations with CAM4.0, an updated version of CAM3.0. The results (figures in the supplementary information) and the main conclusions are qualitatively similar.

\section{Conclusions and discussion}

The dependence of climate on atmospheric mass is explored using a 3D GCM with aquaplanet simulations. The simulation results reveal a nonmonotonic dependence of the global mean temperature, $\overline{T_{s}}$, on atmospheric mass. Within the SP range from 0.9 to 1.5 bar, $\overline{T_{s}}$ decreases with increases in SP due to a convection-circulation-cloud coupled feedback. As SP increases over this range, the moist adiabatic lapse rate increases, leading to upper-troposphere cold anomalies in the tropics and middle latitudes. These temperature anomalies increase the midlatitude baroclinicity and eddy activity. In associated with the above changes, the eddy-driven jet strengthens and shifts equatorward, and the two separate westerly jets merge into a single jet. Moreover, the midlatitude clouds are enhanced and shift equatorward, and the fraction of polar clouds decreases due to the subsidence of the emerged polar cell; both of these changes lead to enhanced cloud radiative cooling. Our results reveal that the abrupt regime transition of the atmospheric circulation (herein reflected by the merging of the two jets) and 

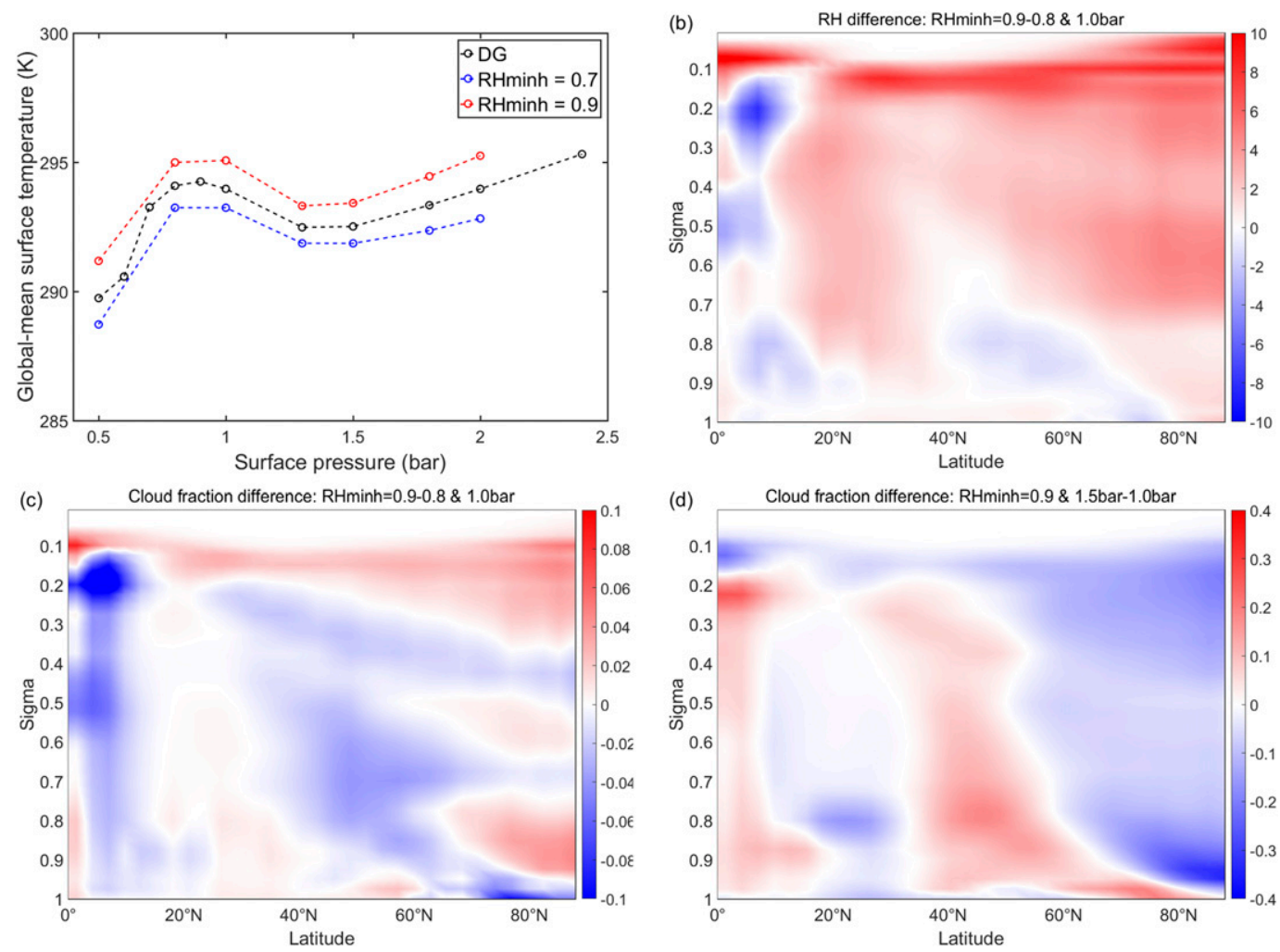

FIG. 13. Results for the simulation group with perturbed cloud parameter. (a) $\overline{T_{s}}$ as a function of SP. (b) The relative humidity differences between the $\mathrm{RH}_{\text {minh }}=0.9$ simulation and the DG simulation $\left(\mathrm{RH}_{\operatorname{minh}}=0.8\right)$ of the 1.0-bar cases. (c) The cloud fraction differences between the $\mathrm{RH}_{\text {minh }}=0.9$ simulation and the DG simulation $\left(\mathrm{RH}_{\operatorname{minh}}=0.8\right)$ of the 1.0-bar cases. (d) The cloud fraction differences between 1.5- and 1.0-bar cases for the simulations with $\mathrm{RH}_{\text {minh }}=0.9$.

its associated cloud responses may lead to the nonlinear dependence of climate on atmospheric mass.

There are cautions that must be noted regarding our results. Our aquaplanet simulations exclude the effects of orography and ocean circulations. Compared with observations, the aquaplanet simulations also have systemic biases in radiation (e.g., reduced planetary albedo) and thermodynamics (e.g., a low Bowen ratio and a strong hydrological cycle). Furthermore, the details of our simulations likely depend on the base state of the particular GCM. Under our experimental setting, there are two separate jets in the control case, and the regime transition of jets ranges from 0.9 to 1.5 bar. With different experimental settings, the SP corresponding to the jet transition may also change. Nevertheless, we believe that our main findings, such as the cold anomalies in the free troposphere due to changes in the moist adiabatic lapse rate and the enhancement of midlatitude eddies and jets, are robust based on well-understood physical arguments. There may be some confidence in the cloud responses associated with significant circulation changes, such as shifts in the cloud belt with the storm track and decreases in polar clouds due to the strengthening of the polar cell. Sensitivity tests in section 6 suggest that the results are robust within certain perturbations of parameters or in another version of the GCM (CAM4.0). It is possible that a different GCM may show a different $\overline{T_{s}}-$ SP dependences, given the climate sensitivities of GCMs are widespread. However, our results reveal at least a possible dependence of climate on atmospheric mass that is robust over certain parameter spaces, and we believe they are worth reporting.

Our findings provide a new mechanism for the effects of atmospheric mass on climate. This mechanism emphasizes the coupling between atmospheric circulation and clouds so that an abrupt regime transition of the atmospheric circulation may induce large cloud responses and radiative forcing. In addition to the merging of jets in this study, there are a number of possible abrupt regime transitions in Earth's climate system, such as the collapse of the thermohaline circulation and the melting of polar glaciers (Lenton et al. 2008), each of which may induce further adjustments and feedbacks if triggered. The effects of clouds have also been largely overlooked in previous planetary atmosphere studies, due to the complexity and uncertainties associated with clouds in climate models. Our results highlight the importance of clouds in shaping climate responses to external planetary parameters, such as atmospheric mass, and call for further exploration.

Acknowledgments. The authors thank three anonymous reviewers for their helpful reviews, Yongyun $\mathrm{Hu}$, Yonggang Liu, 
and Gang Chen for discussion. This research was supported by National Natural Science Foundation of China Grant 41875050 and 41675071 . The supplementary information for simulations in section 6 can be found at https://doi.org/10.1175/JAS-D-200022.s1 (AMS-hosted site) and at https://www.jiniepku.com/ download.html (lead-author-hosted site).

\section{REFERENCES}

Barnes, E. A., and L. Polvani, 2013: Response of the midlatitude jets, and of their variability, to increased greenhouse gases in the CMIP5 models. J. Climate, 26, 7117-7135, https://doi.org/ 10.1175/JCLI-D-12-00536.1.

Bekker, A., H. Holland, P.-L. Wang, D. Rumble III, H. Stein, J. Hannah, L. Coetzee, and N. Beukes, 2004: Dating the rise of atmospheric oxygen. Nature, 427, 117-120, https://doi.org/ 10.1038/nature02260.

Brayshaw, D. J., B. Hoskins, and M. Blackburn, 2008: The storm-track response to idealized SST perturbations in an aquaplanet GCM. J. Atmos. Sci., 65, 2842-2860, https:// doi.org/10.1175/2008JAS2657.1.

Briegleb, B. P., 1992: Delta-Eddington approximation for solar radiation in the NCAR Community Climate Model. J. Geophys. Res., 97, 7603-7612, https://doi.org/10.1029/92JD00291.

— M. Bitz, C. Hunke, H. Lipscomb, M. Holland, L. Schramm, and E. Moritz, 2004: Scientific description of the sea ice component in the Community Climate System Model, version 3. NCAR Tech. Note NCAR/TN-463+STR, 78 pp., http:// doi.org/10.5065/D6HH6H1P.

Charnay, B., F. Forget, R. Wordsworth, J. Leconte, E. Millour, F. Codron, and A. Spiga, 2013: Exploring the faint young sun problem and the possible climates of the Archean Earth with a 3-D GCM. J. Geophys. Res. Atmos., 118, 10 414-10431, https://doi.org/10.1002/jgrd.50808.

Chemke, R., and Y. Kaspi, 2017: Dynamics of massive atmospheres. Astrophys. J., 845, 1, https://doi.org/10.3847/1538-4357/aa7742.

,-- , and I. Halevy, 2016: The thermodynamic effect of atmospheric mass on early Earth's temperature. Geophys. Res. Lett., 43, 11 414-11 422, https://doi.org/10.1002/2016GL071279.

Collins, W. D., and Coauthors, 2004: Description of the NCAR Community Atmosphere Model (CAM 3.0). NCAR Tech. Note NCAR/TN-464+STR, 214 pp., https://doi.org/10.5065/ D63N21CH.

— , and Coauthors, 2006: The formulation and atmospheric simulation of the Community Atmosphere Model version 3 (CAM3). J. Climate, 19, 2144-2161, https://doi.org/10.1175/ JCLI3760.1.

Covey, C., D. D. Lucas, J. Tannahill, X. Garaizar, and R. Klein, 2013: Efficient screening of climate model sensitivity to a large number of perturbed input parameters. J. Adv. Model. Earth Syst., 5, 598-610, https://doi.org/10.1002/jame.20040.

Dima, I. M., and J. M. Wallace, 2003: On the seasonality of the Hadley cell. J. Atmos. Sci., 60, 1522-1527, https://doi.org/ 10.1175/1520-0469(2003)060<1522:OTSOTH >2.0.CO;2.

Ding, F., and R. T. Pierrehumbert, 2016: Convection in condensiblerich atmospheres. Astrophys. J., 24, 822, https://doi.org/10.3847/ 0004-637X/822/1/24.

Dütsch, H., 1978: Vertical ozone distribution on a global scale. Pure Appl. Geophys., 116, 511-529, https://doi.org/10.1007/ bf01636904.

Eichelberger, S. J., and D. L. Hartmann, 2007: Zonal jet structure and the leading mode of variability. J. Climate, 20, 5149-5163, https://doi.org/10.1175/JCLI4279.1.
Emanuel, K. A., J. D. Neelin, and C. S. Bretherton, 1994: On large-scale circulations in convecting atmospheres. Quart. J. Roy. Meteor. Soc., 120, 1111-1143, https://doi.org/10.1002/ qj.49712051902.

Frierson, D. M., 2005: Studies of the general circulation of the atmosphere with a simplified moist general circulation model. Ph.D. thesis, Princeton University, 228 pp.

- J. Lu, and G. Chen, 2007: Width of the Hadley cell in simple and comprehensive general circulation models. Geophys. Res. Lett., 34, L18804, https://doi.org/10.1029/2007GL031115.

Goldblatt, C., M. W. Claire, T. M. Lenton, A. J. Matthews, A. J. Watson, and K. J. Zahnle, 2009: Nitrogen-enhanced greenhouse warming on early Earth. Nat. Geosci., 2, 891-896, https://doi.org/10.1038/ngeo692.

Gregory, J. M., and T. Andrews, 2016: Variation in climate sensitivity and feedback parameters during the historical period. Geophys. Res. Lett., 43, 3911-3920, https://doi.org/10.1002/ 2016 GL068406.

Hartmann, D. L., 2015: Global Physical Climatology. Vol. 103. Newnes, 498 pp.

Held, I. M., 1975: Momentum transport by quasi-geostrophic eddies. J. Atmos. Sci., 32, 1494-1497, https://doi.org/10.1175/ 1520-0469(1975)032<1494:MTBQGE > 2.0.CO;2.

- 2000: The general circulation of the atmosphere. 2000 Woods Hole Oceanographic Institute Geophysical Fluid Dynamics Program, Woods Hole, MA, Woods Hole Oceanographic Institution, https://www.whoi.edu/fileserver.do?id=21464\& $\mathrm{pt}=10 \& \mathrm{p}=17332$.

_ , and A. Y. Hou, 1980: Nonlinear axially symmetric circulations in a nearly inviscid atmosphere. J. Atmos. Sci., 37, 515-533, https:// doi.org/10.1175/1520-0469(1980)037<0515:NASCIA > 2.0.CO;2.

Holland, M. M., and C. M. Bitz, 2003: Polar amplification of climate change in coupled models. Climate Dyn., 21, 221-232, https:// doi.org/10.1007/s00382-003-0332-6.

Holton, J., and G. Hakim, 2012: An Introduction to Dynamic Meteorology. Academic Press, 552 pp.

Hoskins, B. J., and P. J. Valdes, 1990: On the existence of stormtracks. J. Atmos. Sci., 47, 1854-1864, https://doi.org/10.1175/ 1520-0469(1990)047<1854:OTEOST > 2.0.CO;2.

$\mathrm{Hu}, \mathrm{S}$., and W. R. Boos, 2017: The physics of orographic elevated heating in radiative-convective equilibrium. J. Atmos. Sci., 74, 2949-2965, https://doi.org/10.1175/JAS-D-16-0312.1.

$\mathrm{Hu}$, Y., H. Huang, and C. Zhou, 2018: Widening and weakening of the Hadley circulation under global warming. Sci. Bull., $\mathbf{6 3}$, 640-644, https://doi.org/10.1016/j.scib.2018.04.020.

Jackson, C. S., M. K. Sen, G. Huerta, Y. Deng, and K. P. Bowman, 2008: Error reduction and convergence in climate prediction. J. Climate, 21, 6698-6709, https://doi.org/10.1175/2008JCLI2112.1.

Kim, H., and S. Lee, 2004: The wave-zonal mean flow interaction in the Southern Hemisphere. J. Atmos. Sci., 61, 1055-1067, https:// doi.org/10.1175/1520-0469(2004)061<1055:TWMFII>2.0.CO;2.

Lachmy, O., and N. Harnik, 2016: Wave and jet maintenance in different flow regimes. J. Atmos. Sci., 73, 2465-2484, https:// doi.org/10.1175/JAS-D-15-0321.1.

Lammer, H., and S. Bauer, 1991: Nonthermal atmospheric escape from Mars and Titan. J. Geophys. Res. Space Phys., 96, 18191825, https://doi.org/10.1029/90JA01676.

Lee, S., and H. Kim, 2003: The dynamical relationship between subtropical and eddy-driven jets. J. Atmos. Sci., 60, 1490-1503, https://doi.org/10.1175/1520-0469(2003)060<1490:TDRBSA > 2.0.CO;2.

Lenton, T. M., H. Held, E. Kriegler, J. W. Hall, W. Lucht, S. Rahmstorf, and H. J. Schellnhuber, 2008: Tipping elements 
in the Earth's climate system. Proc. Natl. Acad. Sci. USA, 105, 1786-1793, https://doi.org/10.1073/pnas.0705414105.

Li, C., and J. J. Wettstein, 2012: Thermally driven and eddy-driven jet variability in reanalysis. J. Climate, 25, 1587-1596, https:// doi.org/10.1175/JCLI-D-11-00145.1.

Molnar, P., and K. A. Emanuel, 1999: Temperature profiles in radiative-convective equilibrium above surfaces at different heights. J. Geophys. Res., 104, $24265-24271$, https://doi.org/ 10.1029/1999JD900485.

Nakamura, H., and T. Sampe, 2002: Trapping of synoptic-scale disturbances into the North-Pacific subtropical jet core in midwinter. Geophys. Res. Lett., 29, 1761, https://doi.org/10.1029/ 2002GL015535.

Nie, J., Y. Xia, S. Hu, W. Yuan, J. Yang, and D. Ma, 2019: Similarity among atmospheric thermal stratifications over elevated surfaces under radiative-convective equilibrium. Geophys. Res. Lett., 46, 3512-3522, https://doi.org/10.1029/2018GL081867.

O'Rourke, A. K., and G. K. Vallis, 2013: Jet interaction and the influence of a minimum phase speed bound on the propagation of eddies. J. Atmos. Sci., 70, 2614-2628, https://doi.org/ 10.1175/JAS-D-12-0303.1.

Pierrehumbert, R. T., 2010: Principles of Planetary Climate. Cambridge University Press, 674 pp.

Ramanathan, V., and P. Downey, 1986: A nonisothermal emissivity and absorptivity formulation for water vapor. J. Geophys. Res., 91, 8649-8666, https://doi.org/10.1029/JD091iD08p08649.

Sagan, C., and G. Mullen, 1972: Earth and Mars: Evolution of atmospheres and surface temperatures. Science, 177, 52-56, https://doi.org/10.1126/science.177.4043.52.
Sanderson, B. M., 2011: A multimodel study of parametric uncertainty in predictions of climate response to rising greenhouse gas concentrations. J. Climate, 24, 1362-1377, https://doi.org/ 10.1175/2010JCLI3498.1.

Seager, S., 2013: Exoplanet habitability. Science, 340, 577-581, https://doi.org/10.1126/science.1232226.

Som, S. M., R. Buick, J. W. Hagadorn, T. S. Blake, J. M. Perreault, J. P. Harnmeijer, and D. C. Catling, 2016: Earth's air pressure 2.7 billion years ago constrained to less than half of modern levels. Nat. Geosci., 9, 448-451, https://doi.org/10.1038/ngeo2713.

Son, S.-W., and S. Lee, 2005: The response of westerly jets to thermal driving in a primitive equation model. J. Atmos. Sci., 62, 3741-3757, https://doi.org/10.1175/JAS3571.1.

Stephens, G. L., and Coauthors, 2012: An update on Earth's energy balance in light of the latest global observations. Nat. Geosci., 5, 691-696, https://doi.org/10.1038/ngeo1580.

Thomson, S. I., and G. K. Vallis, 2019: The effects of gravity on the climate and circulation of a terrestrial planet. Quart. J. Roy. Meteor. Soc., 145, 2627-2640, https://doi.org/10.1002/qj.3582.

Wolf, E., and O. Toon, 2013: Hospitable Archean climates simulated by a general circulation model. Astrobiology, 13, 656-673, https:// doi.org/10.1089/ast.2012.0936.

- , and - 2014: Controls on the Archean climate system investigated with a global climate model. Astrobiology, 14, 241-253, https://doi.org/10.1089/ast.2013.1112.

Yuval, J., H. Afargan, and Y. Kaspi, 2018: The relation between the seasonal changes in jet characteristics and the Pacific midwinter minimum in eddy activity. Geophys. Res. Lett., 45, 9995-10002, https://doi.org/10.1029/2018GL078678. 